\title{
ON THE INTESTINAL DISCHARGES IN CHOLERA.
}

By E. A. PARKES, M.D., Assistant.Physician to University College Hospital.

THE chemical and microscopic examinations of the discharges from the alimentary mucous membrane, present certain difficulties, and are liable to certain fallacies, which do not occur in the investigation of the constitution of the urine. Whatever abnormal ingredients may exist in the urine, must have been derived from the blood, and have passed, with more or less change imposed upon them, through the secreting textures of the kidney or bladder. But the excretion from the intestinal mucous membrane is, in health, mixed with a mass of extraneous matter, such as the debris of food, the excrementitious portions of certain secretions, etc.; and, in disease, with the abnormal discharges induced by medicines, or even with the medicines themselves. In the case of severe Cholera, however, many of these possible difficulties and errors are avoided. The fæculent contents of the intestines are, at an early period of the disease, expelled; no solid food is taken, or, if taken, is ever tolerated by the stomach; the bile, and probably the pancreatic fluid, is retained; and there is no fear of urine mixing with the stools, for the kidneys are inactive. The Cholera dejections are therefore the produsts of the mucous membrane alone, with the possible addition of certain medicines, or of fluids, which, having remained on the stomach, and then passed into the intestines, have been discharged nearly unaltered.' In the following observations, I believe even these sources of error have been guarded against. In most of the cases I was aware of the treatment which had been employed; and if any fluid that I obtained, was found to contain an obviously extraneous and foreign ingredient, I did not make use of it.

The stools in Cholera, it need hardly be said, consist of two very distinct portions : of a colourless fluid, which is turbid, or, more usually, nearly clear, or perfectly transparent ; and of a sediment, which is white, and of different physical characters, acrording to the period of the case. In several cases I have made analyses of the fluid, and have also made, or caused to be made, microscopic examinations of the sediment. In the following paper I shall first detail the chemical analyses of the supernatant fluid; and subsequently, the microscopic appearances of the cholera-masses in the same cases.

\section{CHEMICAL EXAMINATION OF THE FLUID.}

Two of these analyses were made by Dr. Garrod, the remainder by myself. I have shortened all details as much as possible; and have not included negative experiments, unless of an important kind. Although it has not been possible to analyze, as I desired, all the stools passed during the course of a single case, it will be seen that my observations embrace all periods of the illness in different cases, and indi-

1 This seems to be the case with milk, which often is not rejected by the stomach, and then passes through the bowels so unchanged as not only to give the stool a milky appearance, and to present under the microscope multitndes of oil globnles, but actually, anter standing for some time, to form a kind of cream. 
cate, with tolerable accuracy, the probable course of events in individual patients.

Observation 1. First or second true rice-water stool of the algide stage, from a middle-aged man, who subsequently died. Analyzed by Dr. Garrod.-The stool separated into two parts, on standing: specific gravity of the entire fluid, 1009.16 at $56^{\circ} \mathrm{Fahr}$.; specific gravity of the clear fluid, 1009.40 at $53^{\circ} \mathrm{Fahr}$. ; or if the temperature be taken into account, about 1009.0 ; reaction, slightly alkaline, but well marked; odour peculiar, slightly fæculent.

Heated with a small quantity of nitric acid, the fluid acquired a pink tint, and a precipitate fell; a peculiar odour was developed ; ${ }^{1}$ there was no effervescence. Strong nitric acid destroyed the pink tint. The alcoholic extract gave the tint with nitric acid; showing, in this way also, that it could not be dependent on uric acid. On drying the watery extract, however, and exposing it to the vapour of ammonia, a pink colour again became evident, most probably from the formation of murexide. No urea could be detected. With hydrochloric acid, the purple tint, from the presence of a protein compound, was produced. Acetic acid gave a slight precipitate. There was none of the organic principle of the bile.

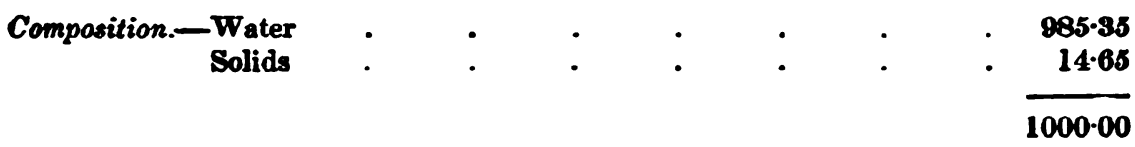

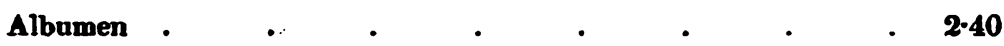

$$
\begin{aligned}
& \begin{array}{l}
\text { Other undetermined matters, including principle coloured by nitric } \\
\text { acid, trace of uric acid, etc. }
\end{array} \\
& \text { Salts, phosphates, and chlorides,-the latter in excess } \quad \text {. } \quad \text { 10-98 } \\
& \overline{14 \cdot 65}
\end{aligned}
$$

Dr. Garrod remarks, that " the ash has nearly the same composition as that of the serum of the blood, the chlorides being greater in amount than the phosphates."

Observation 2.-Stool passed by a man agcd about 50, thirteen hours after the commencement of the attack, and six before death. Algide symptoms intense. - The stool separated, on standing, into two parts. The supernatant fluid was perfectly watery and limpid, passing readily through fine filtering paper. Reaction, markedly alkaline ; odour, peculiar, and faint,-perhaps slightly feculent; specific gravity, 1009.5, at $49^{\circ} \mathrm{Fahr}$.

The liquid became hazy by heat, and the peculiar odour was rendered more intense. A drop of nitric acid increased the turbidity; a few more drops considerably increased it, and produced a very faint, but decided violet, tint; a further addition of acid destroyed this colour, and gave a light yellow tinge. A tolerably copious precipitate fell. When acidulated with acetic acid, the yellow prussiate of potash, and the bichloride of mercury, both gave precipitates. The ash of the fluid was perfectly white; it effervesced with nitric acid; the solution of the salts was strongly alkaline. There was no urea, nor uric acid, in the fluid. 


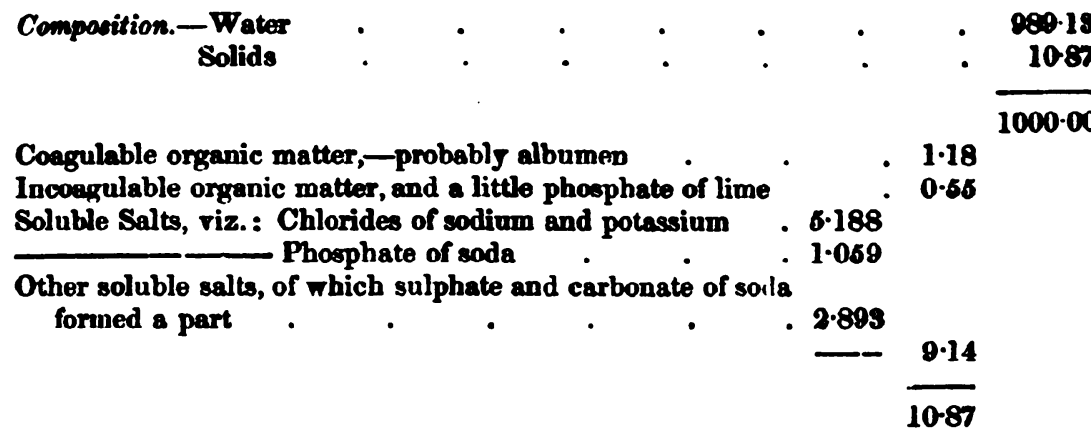

Observation 3.-Last stool passed by a woman, aged 28, in the deep algide stage, six hours before death; cramps had been severe, but had nearly ceased.-The whole stool was only $3 \mathrm{x}$ in quantity. It separated into two parts : the fluid part was perfectly clear and watery. It was filtered through fine paper. Reaction, alkaline; odour, peculiar,-not at all feculent; the specific gravity was not taken.

Boiling produced no change of colour. A drop of nitric acid produced a little decided effervescence; but no violet tint. A few more drops gave a flocculent precipitate; but there was no change of colour. A very peculiar odour was given off; and a gas was evidently disengaged, as it was now difficult to boil the liquid, on account of its occasional violent ebullition. The odour was certainly different from that of butyric acid, with which it was at the time compared. It was less sharp, and had more of a burnt odour. By adding nitric acid in excess, and boiling for some time, the odour disappeared, and the precipitate more completely separated itself. There was no uric acid. The ash of the fluid effervesced with nitric acid.

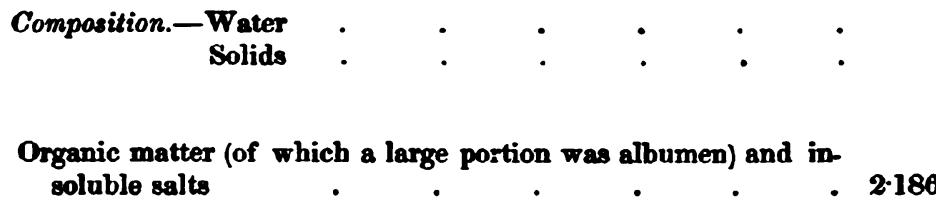

$$
\begin{aligned}
& \text { Soluble salts, viz.: Chlorides, phosphates, and sulphates } \quad \text { 7.520 } \\
& \text { 9.706 } \\
& \begin{array}{r}
990.294 \\
\quad 0.706 \\
\hline 1000.000
\end{array}
\end{aligned}
$$

Observation 4.-One of the last stools passed by a middle-aged man, in the deep algide stage, who subsequently died. It had the usual physical appearance, and was alkaline.

Dr. Garrod was kind enough to examine it very carefully for urea, and uric acid, but could not detect the presence of either. The organic compound which gives the red or violet tint with heat, and nitric acid, was also absent. The stool contained, as usual, salts, and coagulable organic matter, but the quantities of these were not determined.

Observation 5.-Either the 6th or 7th stool passed by a roman, aged 23. There were severe cramps at the time. The algide symptoms were vell marked, but the patient ultimately recovered.-The stool consisted of two parts, as usual. The fluid was thin, watery, and colourless, but not perfectly transparent. It was not filtered, but drawn off with a pipette.

Reaction, strongly alkaline; odour, peculiar, and very slightly fæculent; specific gravity, 1008.3, at $66^{\circ} \mathrm{Fah}$. 
With heat, a slight haziness occurred. A very small quantity of nitric acid added to the hot fluid, gave a very beautiful violet tint, which boiling for several minutes did not destroy. The addition of more nitric acid at once destroyed it, and the liquid assumed a slightly yellow tinge; a flocculent precipitate fell. The peculiar odour was given out as usual. The ash, but not the fluid, effervesced with nitric acid.

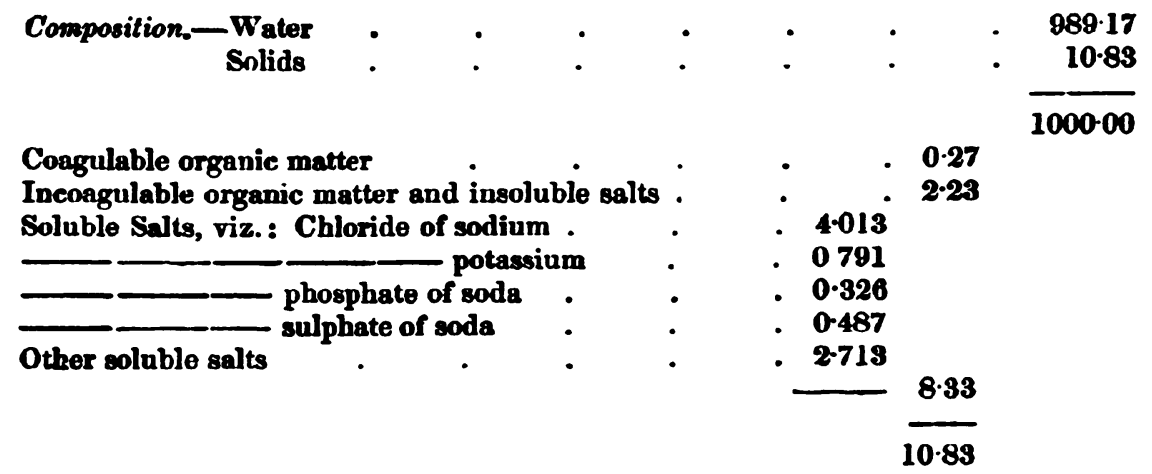

Observation 6. A stool passed by a girl, aged 11, who had been much purged, and had vomited, and had had severe cramps. At the time she passed this stool, the pulse was imperceptible, or nearly so; the eyes were sunken, the surface was very cold, but there was comparatively little cyanotic tinge of the skin, and respiration was easy; six hours aftervards, reaction commenced, and she recovered.

The fluid was thin, colourless, and slightly opaque; it was filtered through coarse paper.

Reaction, faintly alkaline; odour, peculiar, not at all fæculent; specific gravity, 1005.8 at $65^{\circ}$ Fah. By heat the fluid became hazy. It was not treated with nitric acid. The ash effervesced with nitric acid.

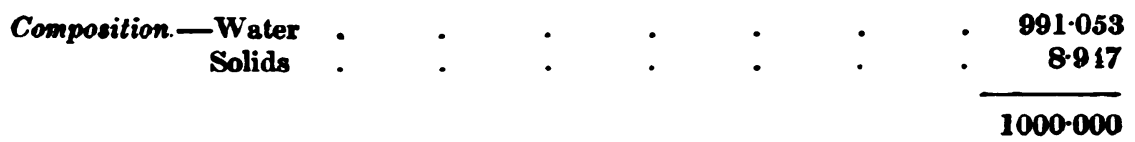

Organic matter, of which an undetermined quantity was albumen $3 \cdot 12$

Soluble Salts, viz. : Chlorides, phosphates, sulphates, carbonates 6827

\section{$\overline{8.917}$}

Observation 7. The last stool passed by a boy, aged 10, seven hours before death. There had been from eight to twelve previous stools during the illness. The algide symptoms were intense, but there were no cramps at any time. ${ }^{1}$-The stool measured $\xi \times \mathrm{xij}$-it was like gruel ; there was a very incomplete separation of the flaky substance from the fluid, until gentle heat was applied, when the flaky substance fell, and left a perfectly clear and limpid supernatant fluid. It was deemed advisable to estimate the solids without separating the suspended solid matter.

Reaction, alkaline; specific gravity, 1010.27, at 52 $\mathrm{Fah}$. The fluid would not pass through the coarsest filtering paper, and very slowly through muslin.

Nitric acid and heat produced a yellowish or fawn colour, there was no red tint; the peculiar odour, rather sharper than usual, was given

1 Cramps are often abeent in children; but in boys of this age they are generally present. 
out. When the flaky substance was separated, the thin fluid gave a flocculent precipitate with nitric acid. The residue had a brownish colour. The phosphate of lime was in unusual quantity, and may have been derived from the unseparated flaky substance which caused the quantity of organic matter to appear large.

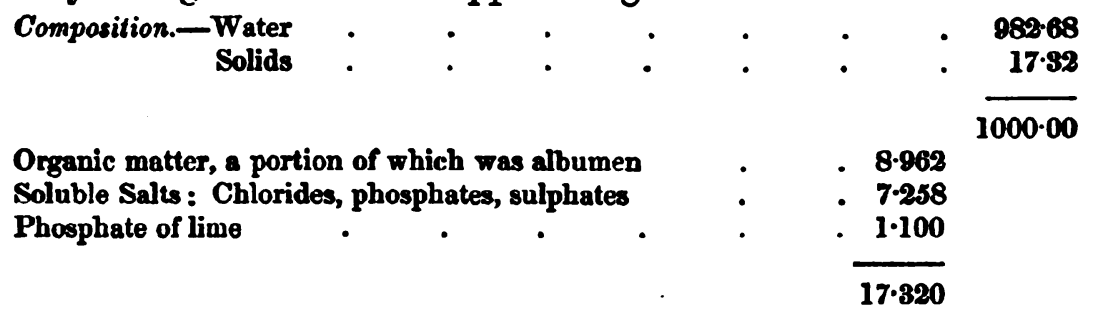

Observation 8. A stool passed by a boy, aged ten, who had presented all the algide symptoms in moderate intensity. Reaction uas just commencing, and in a few hours afterwards, consecutive fever was fully established.1

The stool did not separate readily into two portions ; when it did so, the supernatant fluid was subalbid, and turbid. The liquid was strained.

Reaction, alkaline; odour, peculiar, not at all fæculent; specific gravity, 1014 , at $56^{\circ} \mathrm{Fah}$.

The fluid, when heated, gave out a peculiar odour. Nitric acid, in small quantity, produced a yellowish tint, and a more peculiar and characteristic odour was evolved, but not so well marked as in some of the stools. An excess of nitric acid was added, and the liquid was kept boiling for six hours, when a distinct, but very small, precipitate fell, which was in too small a quantity to weigh.

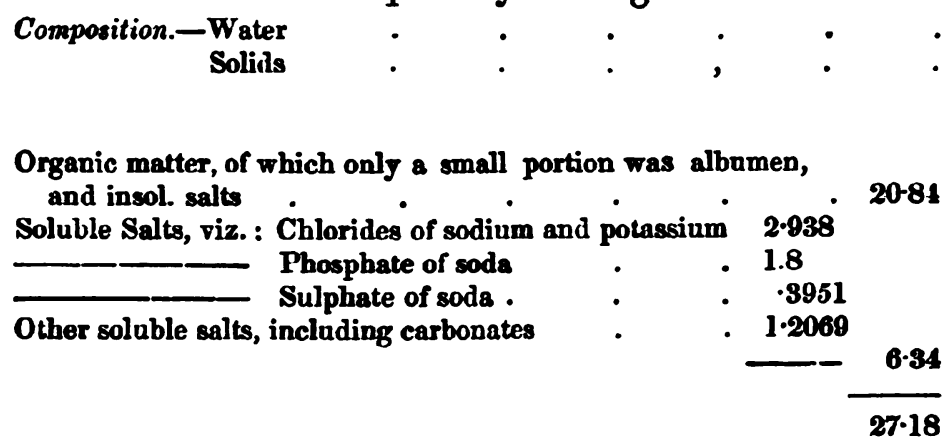

Observation 9. A well marked case in a woman, aged 27 ; the symptoms were, however, nild, though very characteristic; she ultimately recovered. First stool during the period of reaction which had a faculont smell; at the time it was passed, the woman still presented many of the algide symptoms, though the pulse was stronger, and the surface and breath were regaining warmth.

The stool was of a yellowish-white, or subalbid colour, and separated into two portions on standing; the upper portion was whitish-yellow,

1 This patient did not pass urine for fifty-three hours; he then passed abont ten ounces of clear yellow urine; after standing for twenty.four hours, there wa no sediment. The specific gravity was 1.016, at a temperatnre of $56^{\circ}$. By heat and nitric acid the fluid acquired a light red tinge, and about one-third of its bulk of albumen was thrown down. Evaporated to onesixth, and treated with nitric acid, it exhibited, after twenty four hours, no nitrate of urea. It was not tested with Pettenköfer's test for choleic acid. 
thick, and turbid; the sediment was greenish-yellow, granular and dense, and with a decided fæculent smell.'

Fluid filtered through coarse paper. Reaction, faintly alkaline : specific gravity, 1008.91, Temp. 55० Fah.

When boiled for ten minutes, the colour changed, and became of a light red, or fawn tint-the liquid continued alkaline-a peculiar odour was given out, which was not fæculent-there was no ammonia evolved. A few drops of nitric acid added to the hot liquid, gave a dark red, or brown colour; a copious precipitate fell, and the usual odour was given out. After boiling for an hour and a half, the red colour was unchanged. An excess of nitric acid, however, at once destroyed the colour, and the liquid became of a light yellow tint. It appeared as if a portion of the precipitate was re-dissolved. The ash effervesced with nitric acid; the solution of the salts was strongly alkaline.

Hydrochloric acid, boiled with the liquid, gave a slight, but very distinct purple tinge, and a precipitate fell ; a great excess of acid neither destroyed the colour, nor re-dissolved the precipitate. Sulphuric acid gave a reddish tint, and a flocculent precipitate. Uric acid was not tested for; but after some days keeping, the fluid had acquired a smell very much like stale urine.

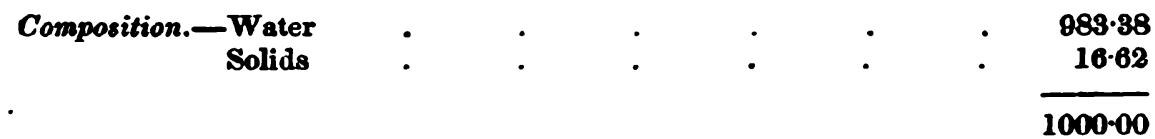

Coagulable organic matter not redissolved by excess of nitric acid $1 \cdot 48$

Incoagulable organic matters $. \quad . \quad . \quad 6 \quad 6.055$

Soluble and insoluble salts, the former consisting of chlorides,

phosphates, sulphates, and carbonates . . . 9.085

$\overline{16 \cdot 62}$

Observation 10. A boy, aged 15, attacked with Cholera. Subsequent reaction and febrile symptoms; then recurrence of rice water purging. The stool was taken at this time. Ultimate recovery.

The stool separated into two parts by rest. The fluid part was watery, but turbid, and of a very light brown colour; it had no freculent smell. The sediment was greyish-white, and was divided into two strata ; the upper whiter, more flocculent, and less granular, than the lower. The fluid portion was filtered through coarse paper.

Reaction, markedly alkaline; specific grarity, 1017.83, at $45^{\circ}$ Fah.

Heated with nitric acid, it effervesced slightly; a red tinge appeared, which became very much deeper after a few minutes boiling. An ex-

I This woman passed urine, for the first time, thirteen hours after the fair commencement of reaction. It was about five ounces in quantity, faintly acid, and of a yellow colour. Specific gravity, 1.018. It was highly albuminous, and threw down, with heat and nitric acid, a copious precipitate, which occupied nearly one-half of the balk of the fluid. At the same time a very deep red colour was struck by the acid, exceedingly like the colour given by nitric acid to the stool in typhoid fever, only not quite so dark. A portion evaporated to an eighth of its bulk, and nitric acid added, gave no erystals of nitrate of urea after thirty-six hours standing.

A white flocculent precipitate subsided from this urine after a few hours standing. As I had not time to examine this, my friend, Mr. Clorer, examined it, and found the following objects:-

1. Scaly and columnar epithelium.

3. Vibriones.

2. Corpuscles like mucons or exudation corpuscles. 4. Pus corpuscles?

There were no crystalline objects. 
cess of nitric acid being added, and the boiling continued, the colour was partially, but not entirely destroyed. A tolerably copious precipitate fell. Uric acid was not detected.

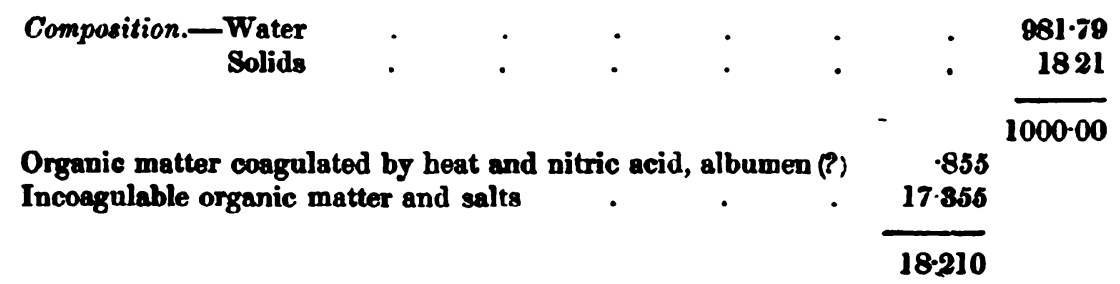

Owing to an accident, the soluble salts were lost after they had been dissolved out from the incinerated mass, and were being evaporated to be weighed. They appeared to be in their usual quantity, and assuming this to be 8 parts in 1000, it leaves 9.355 for the incoagulable organic matter.

Observation 11.-A middle-aged man, after rallying from the cold stage of well-marked Cholera, continued to suffer from diarrhaa. Seven days after reaction, he had a return of what was considered rice water. purging. He ultimately recovered.

The fluid separated into two portions; the sediment was white and flocculent.

Reaction, faintly alkaline; smell peculiar, not at all fæculent; there was not sufficient fluid to take the specific gravity. Heat and nitric acid gave no violet, or red colour, nor at first was there any precipitate ; but after some time, a small flocculent precipitate appeared. The peculiar odour of cholera stools was given out.

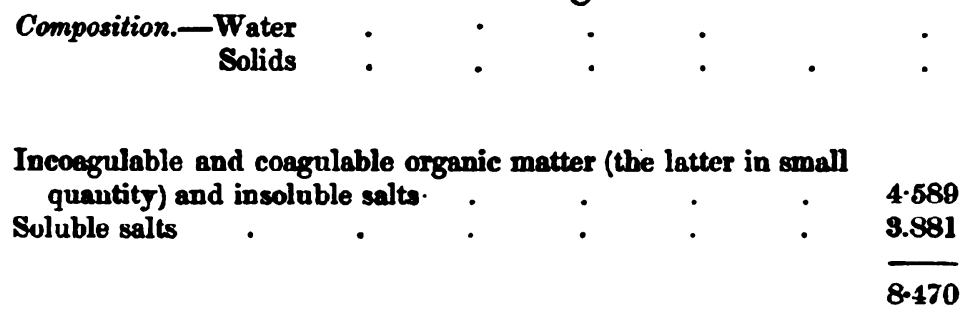

Observation 12.-Fluid taken from the small intestines after death. After filtration, it was distinctly alkaline ; it coagulated by heat alone, and also by heat and nitric acid, which produced no red colour. It contained chlorides and phosphates in abundance. After some days, crystals of triple phosphate formed in it.

Observation 13.-My friend, Mr. J. E. D. Rodgers, has been kind enough to furnish me with the following account of his examination of a specimen of intestinal fluid taken after death.

The fluid was alkaline before evaporation, but after this process it yielded a strongly acid solution.' After incineration, the ash yielded a strongly alkaline solution, which contained carbonates. "Analysis indicated an immense quantity of alkaline chlorides, alkaline and earthy phosphates, and albumen."

In addition to the analyses given above, I have examined several other cases, and have always found, that the thin fluid was alkaline,

I Mr. Rodgers suspected this acid to be the butyric, but was not quite certain on that point. 
and contained an abundance of alkaline chlorides, phosphates, and sulphates, and a certain proportion of albumen. In one or two cases, there has been a trace of iron, possibly from the presence of blood particles, which form an occasional, but very infrequent, constituent of the Cholera stools.

These observations correspond with those of O'Shaughnessy,' Vogel, Wittstock, ${ }^{2}$ Buchanan, ${ }^{3}$ and many others, made during the epidemic of 1832. I shall now proceed to draw such inferences as may safely be done from so small a number of cases.

1. There is no doubt that it is incorrect to speak of the Cholera fluid as the serum of the blood; the fluid is derived from the serum, but is not composed of all its ingredients; it consists of its water, and of its salts, with a very small proportion of its organic elements. If other organic elements of the serum are poured out, they do not remain fluid. The ash effervesces like the ash of the serum, with nitric acid.

2. The Cholera fluid, in its purest form, consists of little else than water, salts, and coagulable organic matter, which is probably albumen. The incoagulable organic matter, or extractive, which is probably an excretion from the intestinal mucous membrane, is reduced to its lowest proportion, (in one case, only .55 in 1000 parts), and possibly, in some cases, may be altogether absent.

3. This soluble incoagulable organic matter, or extractive, which exists in great quantity in healthy fæces, soon disappears from the cholera fluid. It appears to be restored when reaction commences. It raises the specific gravity of the fluid and the proportion of the solids in 1000 parts.

The following observation proves its existence in the mildest form of Cholera, or what may be called, as the algide symptoms were not present, choleroid diarrhœe : $4-$

Observation 14.-Stool from a middle-aged woman, who had had serous diarrhae for two or three days. Vomiting then came on; tuelve hours after its commencement, she had cramps in the extremities. The stool was passed a few hours after the commencement of cramps; at this time there was languor, and the pulse was weak; but there were no other signs of collapse; the skin was warm, and the eyes were not sunken; she speedily recovered. Cholera was ravaging the neighbourhood; and a daughter of this woman was at the time labouring under its developed form.

The stool separated, as usual, into a fluid and sediment.

The fluid was slightly brownish in tint, and semitransparent; the sediment was brownish and flocculent.

Reaction, distinctly but not strongly alkaline. Odour peculiar, not at all fæculent. There was not enough to take the specific gravity.

No effect was produced by heat. A small quantity of nitric acid did

I Report on the Chemical Pathology of the Maligmant Cholera. Highley, London, 1832.

- Simon's Chemistry by Dr. Day, vol. ii, p. 382, and Hoefle, Chemie und Misroscop am Krankenbette. Erlangen, 1848, pp. 87.8.

- Obeervations on the Malignant Cholera, 1832, p. 11.

- In another lens advanced case of premonitory diarrbcea, the extraciive was 3.846, the albumen $\cdot 466$, the phosphate of lime $\cdot 548$, and the soluble salts as muck as $8 \cdot 04$, in the 1000 parts. The sediment was white and focculent; and was found, under the microscope, to consist entirely of undigested food, chiefly vegetables. 
not produce any red or violet tinge; an excess gave a slight yellow tinge, and a precipitate, which had previously formed, separated itself completely. An odour similar to that from other cholera stools was at the same time evolved. The solution of the salts was strongly alkaline.

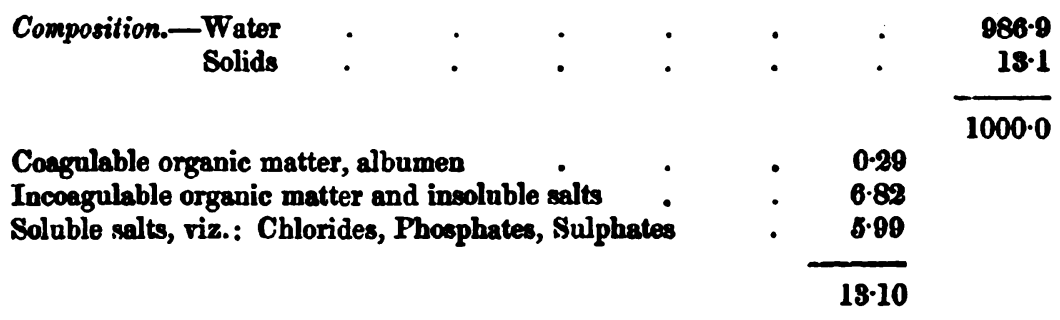

The following tabular view, from which the seventh Observation is excluded, will show more conspicuously the relation of the extractive matter, as well as of the albumen and salts, to the cholera fluid :-

\begin{tabular}{|c|c|c|c|c|c|}
\hline $\begin{array}{l}\text { Period of disease in which the } \\
\text { stool was passed. }\end{array}$ & $\begin{array}{l}\text { Specific } \\
\text { gravity. }\end{array}$ & $\begin{array}{l}\text { Albumen in } \\
1000 \text { parts. }\end{array}$ & $\begin{array}{c}\text { Extractive } \\
\text { in } 1000 \\
\text { parts. }\end{array}$ & $\begin{array}{c}\text { Sol. salts } \\
\text { in 1000 } \\
\text { parts. }\end{array}$ & $\begin{array}{l}\text { Total of } \\
\text { solids in } \\
1000 \text { parts }\end{array}$ \\
\hline 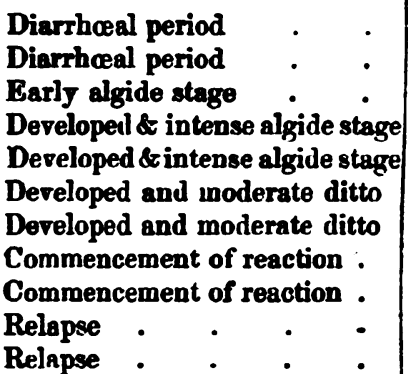 & $\begin{array}{l}1012 \cdot 9 \\
\overline{1009} \\
1009 \cdot 5 \\
\overline{-} \\
1008 \cdot 3 \\
1005 \cdot 8 \\
1014 \cdot 0 \\
100891 \\
1017 \cdot 83\end{array}$ & \begin{tabular}{|c|}
0.466 \\
0.29 \\
2.4 \\
1.18 \\
0.27 \\
\multicolumn{1}{|c|}{2} \\
1.48 \\
0.855 \\
not weighable
\end{tabular} & $\begin{array}{r}3.846 \\
6.82 \\
1.27 \\
0.55 \\
186 \\
2.23\end{array}$ & \begin{tabular}{|c|}
9.04 \\
5.99 \\
$10-98$ \\
$9 \cdot 14$ \\
7.62 \\
8.33 \\
6.827 \\
6.34 \\
$9 \cdot 085$ \\
355 \\
3.881
\end{tabular} & $\begin{array}{c}13.9 \\
13 \cdot 1 \\
14 \cdot 65 \\
1087 \\
9 \cdot 706 \\
10 \cdot 83 \\
8 \cdot 947 \\
27 \cdot 18 \\
16 \cdot 62 \\
18 \cdot 21 \\
8 \cdot 47\end{array}$ \\
\hline
\end{tabular}

4. Although the extractive is thus affected by the intensity of the disease, it does not appear that the salts and albumen are equally so. The analyses are too few to allow me to speak with certainty; but it seems probable that, both in the premonitory period, and in the stage immediately following the algide period, when the pulse is again felt and warmth is returning to the surface, the proportion of effused salts and perhaps of the albumen, may be as great in any particular stool as in the depth of the algide stage. The number of stools, of course, differs in the respective periods.

5. The albumen and the salts do not seem to bear a very constant proportion to each other; but the salts hardly ever seem to be thrown out, without carrying with them a portion of albumen, however small. ${ }^{1}$

In the liquid stools of typhoid fever (by which term I mean the disease described by Lonis), the quantity of albumen in solution, is, as in Cholera, very small; and is never found unless soluble salts, similar to those of the blood-serum, are also present. In one case it was 0.63 , while the solnble salts were 7.24 , in 1000 parts. In a second case it was 0.457 , and the salts were 5.164, in 1000 parts. It would even appear as if some portion of the albumen of the serum were so much more intimately combined with the salts than the remaining larger mass, that it is alone effused when the salts are poured ont. 
The greatest amount of the albumen is very trifling; and I have never seen any other case in which, from the bulk of the precipitate, I was led to infer that it very greatly exceeded in amount the quantity stated in the above analyses.

6. Boehm remarks,' that the discharges probably do not all come from the mucous membrane; but that some of the fluid may be derived from the immense quantity of water drank by the patient. This may be the case sometimes, but there is no indication of such a dilution in the above analyses; the proportion between the salts and the water is tolerably well preserved, and renders it likely that these constituents were both derived from the same source.

7. As in the deep algide stage the excretion of the extractive is arrested, so also, in great measure, is that of the earthy phosphates, which are thrown out so largely by the healthy intestinal surface. In some cases there has hardly been a trace of the phosphate of lime ; in others this has existed in diminished quantity. In no case has it nearly equalled the healthy standard, or approached to the excessive increase which occurs in the stools of typhoid fever. In the cholera stools, the crystals of triple phosphate, although sometimes seen, are infrequent.

8. Nitric acid does not, as Simon supposed, produce any change of colour in the true cholera fluid. When the violet tint does occur, the stool has generally a fæculent smell. The colour is clearly not owing to uric acid, for it is destroyed by an excess of nitric acid, though not, in my experiments, by boiling. Moreover, as Dr. Garrod pointed out, it must be owing to an organic substance soluble in alcohol. It is then either to be attributed to the presence of bile, or to some substance excreted by the intestinal mucous membrane. There is no evidence of bile beyond this colour, and as there is a remarkable retention of this product in cholera, as in dysentery, I am disposed to think the last supposition the most probable one. The same organic matter, if I may speak from the similarity of the remarkable tint produced by the acid, was passing off by the urine in one of the cases of reaction. As uric acid appears to be usually excreted in very small quantity in the first urine passed after cholera, ${ }^{2}$ the colour was probably not attributable to it, and it was indeed dissimilar in shade. ${ }^{3}$

1 Die Kranke Darmschleimhaut in der Asiatischen Cholera, etc., von Dr Ludwig Boehm. Berlin, 1838, p. 15.

- Dr. Letheby has lately made two analyses of urine passed during reaction, in which the proportion both of urea and nric acid is low, while that of extractive (kreatine, kreatinine, and other organic matters) is very high.-(Medical Gazette for December.)

- The same colour, only of a very much deeper shade, is given by the fluid part of the stools in the "fièrre typhoide," and I have also seen it several times in the urine of persons labouring under obscure affections of the digestive organs, not connected, as far as $I$ could make out, with the liver. It is important to remember, as bearing on the question of the nature of ferer consecutive to Cholera, that nrea and uric acid and lreatine are not the only excretions which may be retained in the blood; it is very possible that the peculiar organic compounds, usually excreted by the intestinal mucous membrane, may be also retained, in consequence of the deep injury this membrane has undergone. In other diseases, I have been led to infer, although it is exceedingly difficult to prove the supposition, that the interruption to the secreting function of the intestinal mucous membrane produces serious dis orders in other organs, which may be connected with it in function, or may be called npon to supply the deficiency. I have formerly argued that certain diseases of the liver, of the pan- 
9. Although the inference of Wittstock, drawn from the colour given by nitric acid, that the cholera fluid contained uric acid, is erroneous, because the colour cannot be always obtained, and when obtained, cannot be owing to uric acid, it appears, from Dr. Garrod's first analysis, that a trace of this acid may exist, as it does in healthy serum; Dr. Garrod, in his second analysis, could not detect any, and I have carefully looked for it without success.

10. In many cases, Pettenköfer's test for the organic principle of bile has been used, but no trace of this substance has been found.

\section{MICROSCOPIC EXAMINATION OF THE SEDTMENT IN THE STOOLS, THE SO-CALLED " CHOJ.ERA MASSES."}

Many stools receive the name of " rice-water", which have no claim to this appellation. The sediment in the true rice-water stool is perfectly white, in flocks or little shreds, and is exceedingly light. Sometimes, the entire stool seems not to have a greater specific gravity than the fluid separated from the sediment. This lightness may be illustrated by the following fact:-The whole flocculent substance from a stool which measured more than a pint in quantity, and which was well washed and dried, in order that it might be submitted to ultimate analysis, weighed only four grains.

The most accurate microscopic examination of the cholera masses are those made by Boehm in 1832, and described and figured in the work to which I have already referred. His descriptions, however, apply almost entirely to the fluid contained in the intestines after death, and he does not seem to have bestowed equal attention on the sediments of the stools. As the proper comprehension of Boehm's admirable researches is essential to the discussion on this subject, I shall, as briefly as clearness will permit, detail his opinions.

In the first chapter, Boehm describes minutely the changes in the epithelium of the intestinal mucous membrane in Cholera. In the second chapter, he describes the microscopic character of the cholera masses. After saying that, in all languages of Asia and Europe, the epithets flocculent, creamy, like groats-broth, like rice-water, etc., have been applied to the intestinal fluid, he goes on to say that the various products, however different to the naked eye, described under these terms, may be all referred to changes in the epithelial coat. The thin fluid, however, he decides to be undoubtedly a secretion from the blood, which is poured in large quantity through the diseased intestinal membrane. The varieties of the intestinal contents depend on the varying proportions of this secretion and the cast-off epithelial particles, and on changes in the latter. He then enumerates the several varieties. The fluid was like milk when the quantity of secretion was great, and the epithelial particles were all separated from each other; it was purulent or creamy when the epithelium, separated into its finest elements, was scantily diluted with the secretion; it was flocculent when, with a pro-

creas, and less frequently of the kidneys, follow large and irreparable destruction of the mucous membrane of the colon in tropical dysentery. Some affection of these organs is not uncoumon after mild attacks of Cholera ; it may be, possibly, from a similar cause. 
fuse secretion, the epithelial particles were not separated, but cohered together, and under the microscope presented flat lamellæ if they came from the smooth mucous coat, or crooked cylinder-like masses, or tubes, domes, or glove-like cases, according as, more or less perfectly cohering, they were shed from the apices, bases, or entire surfaces of the villi, or from the interior of the follicles; it was like rice-water when the flocculi, in smaller quantity, swam in a slightly turbid secretion; it was like oatmeal-broth, when the larger epithelium masses were of various colours, white or greyish green, mixed intimately with each other, assuming, from the scanty secretion mixed with them, a pulpy consistence. When the cholera masses were adherent, this was owing to the partial separation of large patches of epithelium, the further mixing of which with the general contents of the intestine was prevented by death. Boehm then goes on to describe the mucous intestinal contents (which, he says, are rare as long as Cholera is acute), the bilious contents seen at the end of the slighter cases, and the bloody contents seen in some of the severest cases. With these last observations I shall not concern myself at present. Boehm makes one very important observation, viz., that while in the severest cases of Cholera epithelial particles, in immense quantities and with the sharpest outlines, are found on the iliac side of the ilio-colic valve, on the other side of the valve their number at once diminishes in an extraordinary manner, and sometimes they are not seen at all. He accounts for this by supposing that the epithelial coat of the small intestine is soluble in the fluid poured into the large intestine. He says also, that he yet seldomer found pyramidal epithelium particles in the discharges, although there was a quantity of flocculi, which, at the end of the chapter, he describes as composed of semitransparent long strings of an elastic consistence, so that, after being pressed between plates of glass, they recovered their form. These flocks often enclosed little crystals of a rhomboidal form, which, as they also occurred in the cholera fluid, seemed to imply that these elastic shreds might arise from coagulation of some material, which perhaps, he says, owed its origin to solution of epithelial fragments. ${ }^{1}$

In some respects, it would be difficult to describe more accurately the contents of the intestines after death ; in no other disease are such beautiful specimens of epithelium seen, and their several conditions cannot be better described than they are in Boehm's work. But the account of the flocks of the stools is meagre and unsatisfactory ; and Boehm appears to me to have even overlooked some elements in the intestinal contents. ${ }^{2}$

\footnotetext{
Op. cit. pp. 10 to 35.

2 I have not been fortunate enough to meet with any detailed observations made during the present epidemic in St. Petersburg or in Berlin, on the intestinal discharges. From some very interesting debates, however, in the Gesellschaft fur wissenschaftliche Medicin of Berlin, reported in Wie Medicinische Reform for September, October, and November, it is apparent that Boehm's opinion of the extreme importance of the casting off of the epithelinm is considered erroneous. This is not only maintained by Virchow and the partisens of the opinion which regards Cholera as a general blood disease, but also by Leubussler and others, who consider all symptoms as sequences of the disease of the intestiual mucous membrane, and who, it might have been supposed, would have attached much importance to changes in the epithelial coat. Thus Ieubuscher says that 'he cannot consider, with Boehm, the essence of Cholera to be repre-
} 
Before proceeding to this point, I shall subjoin a few microscopic observations on the stools. I was anxious to have these made by independent observers, so that no hypothesis of my own might be supposed to have biassed me. The names of the gentlemen who so kindly complied with my request, is an ample guarantee for the extreme accuracy of the observations. The numbers refer to the corresponding analyses of the fluid of the same stool.

Observation 1. Early algide stage.-Examined by Dr. Jenner, with a power of 400 diameters.

“ 1 . Some closely aggregated amorphous, very fine granular matter, rendered somewhat more transparent by acetic acid.

“2. Numerous minute granules, the largest transparent and yellow, surrounded by a dark border, the smallest dark and opaque; acetic acid rendered some of the granules more transparent; liquor potassæ dissolved a few, and rendered others more transparent; boiled in ether for seven minutes, they appeared undiminished in number and unaltered in appearance.

“ 3. Organic corpuscles, similar to those described subsequently (Observation 6, No. 3), but much fewer in number, and generally smaller; many of them imperfectly formed, the capsule enveloping them being indistinct, so that they looked like a simple aggregation of black and yellow granules.

“ 4. A few semitransparent, peculiarly smooth granules, unaffected by cold liquor potassæ or acetic acid.

"5. No epithelium particles, no pus globules, nor blood corpuscles, either red or white."

Observation 2.-Developed and intense algide stage. Examined by Professor Ellis.

" The white, flaky substance, suspended in the rice-water stool, consists of a clear transparent basis, which contains a granular material and cells.

"Granules.-The granular material is seen on the surface of the mass, and is collected here and there into patches of uncertain size and irregular form ; the molecules composing it are very minute.

"Cells.-The cells are strewed thickly through the mass; and, speaking generally, they may be said to be rather larger than the white corpuscles of the blood. In many parts they seem to be arranged in lines, but this appearance may be due to only a certain number coming into focus at the same time.

"Form of cells.- Some of the cells are roundish in form, though none are circular; and many (perhaps an equal number) are oval or elongated. The lengthened cells are about the size of the others in their short diameter.

"Contents of cells.-Both sets of cells have finely granular contents, and a dark defined circle round them.

\footnotetext{
sented by this throwing of of epithe!ium; this is only a secondary process; " die Abstos. sung ist immer nur ein secondärer Prozess,"-(Op. cit. Nor. 3, p. 124.)

It may not be uninteresting to mention that, in these debates, are many important details of the "diphtheritic inflammations" of various organs, which occur in the consecntive fever.
} 
"Size.-The statement respecting size must not be taken too literally, for many cells are larger than the size stated, and many are smaller.

"Action of acetic acid, equal parts of acid and water. Acetic acid causes the mass to shrink and become more transparent. The cells become very indistinct, being in some cases scarcely recognizable, even where the material is thin. But where the mass is thick, the granular material comes more distinctly into view. Of course the fibriform appearance is lost ; the acid seems to gelatinize the mass.

"Nature. The material resembles exudation mass more than any other substance."

Observation 3.-Developed and intense algide stage. Examined by Professor Sharpey.

“ 1 . No characteristic epithelium particles to be seen.

“2. Slimy flakes, containing, scattered about, irregular-shaped particles, and small molecules.

“3. A few white finely-granular corpuscles; some round, others of a more or less irregular shape; in size a little smaller than the pale corpuscles of the blood."

There may have been other matters; but Dr. Sharpey had time to make only a cursory examination.

Observation 4.-Developed and intense algide stage. Examined by Mr. Hillman; Mr. Quekett, of the College of Surgeons, was kind enough to confirm the observation, and to make sketches of the objects, which I possess.

"1. Squamous epithelial particles; none of the columnar form. cles.

“2. Nucleated and granular bodies, resembling exudation corpus-

" 3. A small number of blood corpuscles.

“4. Irregularly-shaped flattened cells, with single large central nuclei ; rather larger in size than the exudation corpuscle.

"5. Membranous shreds, resembling basement membrane."

Observation 5.-Developed and moderate algide stage. Examined by Mr. Clover. Unfortunately it could not be examined till four or five days after it was passed. There was a quantity of granular matter, and scaly and columnar epithelium.

Observation 6.-Developed and moderate algide stage Examined by Dr. Jenner.

“1. Colourless, semitransparent, amorphous, membranous flakes; dissolved or rendered transparent by acetic acid or liquor potassæ. Boiling ether has no effect upon them (albumen?)."

“ 2. Semitransparent fibres, lying in close apposition; perhaps united by No. 1, or may be only the same matter arranged in striæ. They were seen most distinctly at the parts of the field in which the tissue had accumulated in the thickest masses. Liquor potassæ dissolved them, or rendered them very transparent (fibrine?).

“ 3. Organic corpuscles; round, oval, irregularly oval, or pointed at one end, and rounded at the other; more or less spherical, finely-granular on the surface, and containing, in their interior, minute granules, varying in number from six or eight, to sufficient to fill the entire corpuscle. 
Some of these contained granules were mere black points; others were transparent and yellow, with dark margins. In size, the round corpuscles varied from 1-4000 to 4-5000 of an inch in diameter. The oval corpuscles were about $1-4000$ in breadth and 4-5000 in length. They had both a faintly-yellow tint. Boiled in ether for seven minutes, they were unchanged.

“4. Granules similar to those described in observation 1, No. 2.

“5. One large granular body, semiopaque and yellow; 1-1000 of an inch in diameter; unaffected by acetic acid.

"6. Vibriones in great numbers. Two or three oval transparent bodies placed end to end. When the stool was kept, these fungi increased in numbers."

Observation 7.-Intense algide stage. No cramps throughout illness. Examined by myself. Power of microscope, 400 diameters.

1. Amorphous finely-granular matter.

2. A few molecules.

3. No epithelium or blood corpuscles.

In this case the flaky matter did not separate from the thin fluid till gentle heat was applied; it then formed a confused sediment, which had not the usual flocculent appearance. Mr. Bowman saw this stool, and confirmed the above observation.

Observation 8.-Commencement of reaction. Examined by myself. Power of microscope, 400 diameters.

1. A large quantity of transparent gelatinous matter, completely dissolved by acetic acid.

2. In the meshes of this matter, many dark or yellowish granules, unaffected, or nearly so, by acetic acid.

3. In some few cases, these granules were aggregated together, and formed little masses; whether then surrounded by a cell-wall could not be determined.

4. One or two large cells, containing two or three central granules.

5. No epithelium. After a long examination, one or two particles were seen, which looked like debris.

Observation 9.-Commencement of reaction. Examined by myself, immediately after it was passed.

There were a few epithelial scales, and granular and molecular matter, but hardly any of the peculiar corpuscles formerly described.

Observation 10.-Relapse. Examined by Mr. Quekett and Mr. Hillman.

“ 1 . Small masses of biliary resin.

“2. Granular matter, similar to that seen in mucous corpuscles, and such as is obtainable by squeezing the follicles of the intestinal canal.

" 3. Portion of muscular tissue (adventitious).

"4. No epithelium-no exudation corpuscles-no blood."

Observation 11.-Relapse. Examined by myself.

To the naked eye, the sediment appeared partly finely-granular and partly flocculent,-not at all unlike some true Cholera masses. It consisted entirely of shreds of striped muscular fibre (adventitious), of particles, apparently of undigested food, and of molecular matter. No dark yellow granules were seen; neither was there any appearance of epithelium, nor of blood. 
Observation 12.-Fluid from intestine. Examined by myself.

1. Epithelium particles very numerous.

2. Organic corpuscles, about the same size as the pale corpuscles of the blood, finely granular on the surface, and contrining from six to twelve dark yellow or bluck granules. Acetic acid caused no appeurance of nuclei.

3. A few red blood corpuscles, very much altered and irregular in outline.

4. A few cells, like immature epithelial particles, small and irregular.

5. Granules of the same size as those described in No. 2, but free.

After several days' keeping, the fluid was again examined, when the sime elements were seen, with the addition of a few crystals of triple phosphate.

Olservation 13.-Fluid from Intestine. Examined by Mr. Rodgers.

An immense quantity of epithelium was seen. A dried specimen exhibited a lurge quantity of crystals of alkaline chlorides, a few crystals of phosphate of ammonia and magnesia, and a little phosphate of lime.

Observation 14. - Cholervid diarrhaa. Examined by Mr. Clover and myself.

Epithelial scales, granular matter, and shreds of vegetable fibre and cells derived from food, were observed.

In addition to the above examinations, I have made some others, which agree completely with them, but which, to avoid repetition, I shall not here insert.

These observations, made by independent observers, have a remarkable uniformity among themselves, hut differ completely from Boehm's descriptions. In the true Cholera masses, there are the fibres to which he alludes; but there exist also corpuscles, peculiar granules, and an amorphous flaky matter, which he has not noticed in the stools, nor in the contents taken from the small intestine after death. In both these situations, these elements exist in abundance, though mixed, in the intestine, with an immense quantity of epitheliun, which may possibly, in some cases, obscure them, or cause them to be overlooked.

I do not think any one who had ever seen these corpuscles, could for a moment suppose them to be any modification of broken down epithelium, or to be immature and imperfectly-formed epithelial nuclei. They are different in size, and in all their physical appearances; and, moreover, it must be remembered, that cylinder epithelium is coufessedly scarcely ever seen in the cholera stools; und that if it were so seen, and could by any change or breaking down form either the corpuscles or the granules, we ought to be able to find ull grades and phases of the change. Neither can it be considered probable that the epithelium of the small intestines is soluble in the fluid of tile large, and that then, by deposition, it forms these corpuscles, or the fibres which Boehm describes. In the fluid of the small iıtestines, the epithelial particles often preserve their sharp and definite outline for days, although they occasionally do seem to break up. It is by no means probable that the fluid effused into the coecum, which is doubtless of the same nature as that from the whole canal, can possess any such solvent power.

If not epithelium, can these be mucous corpuscles and granules vol. $\mathbf{I}$. 
thrown off, as it were, by an intense catarrh of the mucous coat?' In reply to this, it may be argued : 1 , that these bodies are much smaller than the large corpuscles with the central granules, seen in mucus; the granules are of a different kind, are differently arranged in the interior of the cell, and are differently acted on by acetic acid. 2 . It is not likely that mucus would be secreted in such enormous quantity, while the usual excreting functions of the mucous membrane are evidently totally abolished. 3. If these corpuscles are mucous, why should they not appear through the whole course of the disease, instead of being confined to the deep algide period? They are not seen in the premonitory diarrhœa, nor after the algide stage; and disappear when the pulse and the warmth of the surface are returning. Now, it seems unlikely, that if they are formed by an intense irritation of the mucous coat, they should so rapidly disappear. I do not wish, however, positively to contend that these corpuscles are not mucous, since I have not compared them, as I hope soon to do, with the intestinal mucous corpuscles in other diseases.

But whatever be the nature of these corpuscles, it seems to me impossible to consider the fibres and gelatinous-looking flakes, mucus. If they are so considered, everything which appears on the surface of a mucous membrane may be called mucus, without any regard to the nature of the action which has been exerted upon the transuding blood fluid, by the textures through which it passes. These fibres and flakes, in all respects, chemical and microscopical, resemble those seen in the so-called inflammatory exudation matter, and it is in the highest degree probable that they owe their origin to effused blood-plasma, which assumes with great rapidity a low, ill-defined, and non-progressive organization. This opinion is rendered still more probable by the fact, that other elements of the blood are effused in the cholera fluid, and that the plasma itself is certainly poured into the solitary and Peyerian glands, (distending their capsules to a great extent,) and perhaps into the entire mucous membrane.

Boehm alludes very briefly to the possibility of this occurrence. He writes :-

"In previous observations, carried on to determine the nature of the flocculent substance, that opinion was most likely, which considered that together with the serous element of the blood, the so-named albuminous, or plastic material, transuded in a dissolved form into the intestinal canal, and then separated in the form of flocculi. In this case, however, the flocculi would naturally exhibit no organized structure and arrangement." 2

Boehm certainly appears to have been a little biassed by his observations on the great desquamation of epithelium, when he did not proceed to prove that this unorganized plastic matter was not present, an observation it was certainly incumbent upon him to make.

With regard even to the separation of the epithelium, although, from the facility with which this structure is shed, even during certain ordinary healthy processes, it does appear probable a priori, that it would be

1 This would probably be the opinion of Andral, who has alrealy (Gazelle Médicale, No. 33, 1817) called this snbstunce " molifiel inucus."

Op. Cit., p 19. From the size of Bothmis plates, it appears probable that his microscope was not of sufficient power to (enable hin to spe the corpuscles. 
largely thrown off in Cholera, there is absolutely no proof that it is so thrown off, until after the death of the patient. The stools contain none, or a quantity not more considerable than is present in common diarrhoea, if even so much. 1 If the epithelium is separated, during life, what could prevent its passing off? It cannot surely be separated and yet retained. Is it then so broken up that it caunot be recognized? This is impossible. Boehm himself accounts for this difficulty, by assuming that the epithelinm is dissolved in the fluid of the large intestine; but this is, in the first place, unlikely; and secondly, is not indicated by analysis. Besides, if during the whole co:irse of Cholera, epithelium is thrown off, how is it that we find it after death in such great abundance? ${ }^{2}$ Is it not most likely that the epithelium does not really separate in any quantity during life : but that after death, leing continually immersed in the fluid which fills the intestines, and being possibly, in some measure, rudely shaken by the previous rapid transit of the Cholera fluid, it may separate itself more or less completely from the basement membrane, and divide itself more or less minutely into its smallest elements, according to the length of time after death, the violence used in opening the intestine, and other obvious circumstances ? ${ }^{3}$ It is quite certrin that the sereral varieties of the stools, such as milky, chalky, \&c., are given, not by epithelium, but by very small granules. In the milky stools, there is often a complete " molecular base."

It appears to me the most simple, and the most likely view to consider all the flocculent matter of the true Cholera stool, cells, dark yellow granules, fibres, flakes, and amorphous matter, to be but modifications of the same substance, viz., fibrine. The granules appear to form, by aggregation, little masses, round which a cell wall forms in the way which, as pointed out by Henle, occurs in certain inflammatory exudations, or perhaps cells may form from the liquid plasma, as in the low organization taking place in the follicular deposit of typhoid fever.

Whether this be the case or not, it may be considered probable that the microseopic forms now referred to, co exist in their greatest perfection with the purest type of the Cholera fluid. They are effused while the disease is at its acme. Immediately after the algide stage, in the first stool of reaction, they become indistinct, and finally disappear; the effusion of fibriue into the intestinal canal appears to bave stopped; the sediment of the stools consists now only of amorphous matter, a few perhaps of the peculiar granules, and a little epitheliun. It may be mistaken, however, if judged only by the eye, for a true Cholera mass, although it does not contain the characteristic elements.

I It probable, howerer, that in the period of reaction especially, there is a great tendency to desquamation, and that one form of consecntive fercr is complicuted with this.

In order to account for the great quantity of floccnlent matter found after death, and the small quantity passed in the stool, I formerly, believing the matter to be of the same hind in loth, suggested that the thinner portions only might pass off; bnt this explnnation is unneceusury, if the mpinions adranced abuve are correct.

3 The epithelium of the gall.bludder, in other diseases besides Cholera, separates in this way anter death, particularly where the bile is watery.

I Inst state, however, that I hare met with two or three stools, passed during the enld stage, in which the focculent matter appeared granular anil amorphous. But these were all nild cases, and there were foreign unfters in the stool which obscured the view, and I may mention that in these cases it was singular that there was very little lividity of the akin. 
Then gradually the quantity of Cholera fluid lessens, and finally, bile pigment appears, and the stools lose altogether the Choleraic character.

Want of space compels me to dismiss these most important topics, with theflindication merely of the chief points of interest. I hope on a fycure occasion, to be able to adduce additional facts in corroboration, or mgdification of my views, and to enter more fully into the question of the relation of the individual elements of the Cholera dejections, to the general phenomena of the disease.

\section{CONTRIBUTIONS TO THE PATHOLOGY AND TREATMENT} OF TROPICAL FFVERS.

By JAMES BIRD, A.M., M.D., formerly Surgeon to the Enropean General Hospital at Bombay, and late Physician General, Bombay Army.

(Continued from p. 60.)

\section{I. REMITTENT FEVER.}

The tendency of intermittents, when unchecked, to pass into remittents, and of the latter to change again to the intermittent form, during the transition from the hot to the cold season, shows the intimate relation of these varieties of fever. In 1821, the rainy season at Kaira was unusually light, the weather consequently hot, producing among the men of the Horse Artillery a great amount of hepatic disease, but comparatively few cases of remittent fever. The latter, however, was prevalent in H.M. 17th Dragoons, who were located leerard of fertile, marshy ground that lies south of the cantonment towards Cambay; while the site of the latter was lower and more favourable to malarious emanations, than was the locality of the Horse Artillery Burrack. Here a slight elevation and comparative dryness of soil produced only intermittents and attacks of hepatic disease ; there a lower level and damper situation, abounding with pools of water, which dried up as the weather got hot, gave origin to remittents.

The Kaira district of Gujerat, in which the dragoon cantonments were situated, is a flat, sandy country, where the land is well cultivated and fertile, producing abundance of rice, wheat, and other grains. The soil is a mixture of sand and vegetable mould, the substratum of which is a granular carbonate of lime, here and there elevated into hillocks, or sloping in gentle declivities towards the beds of the rivulets, which have a slow, almost stagnant, course towards the sea. The nature of the soil, and flatness of the land, admit of the country being easily flooded during the rainy season, which begins in the middle of June and continues till the end of September. While the rain is actually falling, intermittents and dysenteries are the prevailing complaints; but towards the termination of the season, when vegetable decomposition begins to take place, and the vapour which arises from damp situations during the day is seen at evening to hang over them in the form of a white haze, remittent fevers of a violent nature become general. From the middle of September to the middle of November, when the climate is humid, hot, and oppressive, these fevers rage with great severity, and in various forms, according to the peculiar atmospheric condition of particular seasons, and prove very fatal to recentlyarrived Europeans. 